DOI: $10.7242 / 1998-2097 / 2018.4 .4$

УДК $581.132 ; 633.88 ; 450.2$

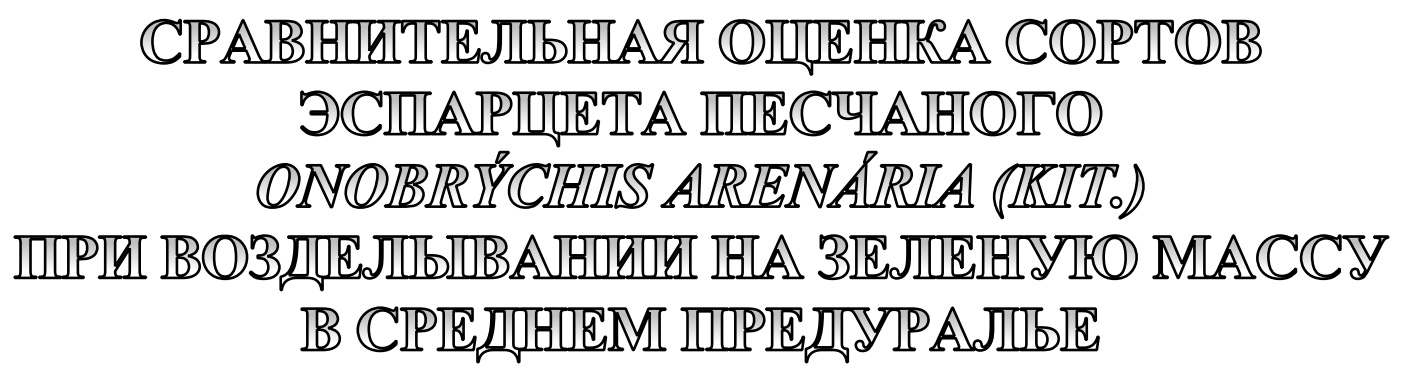

Н.Н. Матолинец, Пермский научно-исследовательский институт сельского хозяйства

В.А. Волошин, Пермский научно-исследовательский институт сельского хозяйства

Приведены результаты сравнительной оценки пяти сортов эспарцета песчаного Onobrýchis arenária (Kit.), выведенных в различных селекционных центрах, в условиях Пермского края. Сообщаются данные по густоте всходов, полевой всхожести, прохождению основных фенофраз, перезимовке, урожайности зеленой и сухой массы. Установлено, что в первый год жизни в условиях 2015-2016 годов все сорта эспарцета песчаного показали себя культурой озимого типа развития. Во 2-й год жизни максимальный сбор абсолютно сухой массы в целом за сезон - 6,24 т/га получен у сорта СибНИИК-30, наименее урожайным оказался сорт Павловский - 4,21 т/га. Биохимический анализ зеленой массы пяти сортов эспарцета песчаного показал, что данная кормовая культура обладает высокой питательной ценностью для сельскохозяйственных животных. Проведенные исследования показали возможность интродукции эспарцета в сельское хозяйство среднего Предуралья, но необходима целенаправленная селекция этой культуры для условий данного региона. Полученные результаты в дальнейшем будут полезны для работы Государственной комиссии РФ по испытанию и охране селекционных достижений при формировании Государственного реестра сортов (селекционных достижений), допущенных к использованию на территории различных регионов России.

Ключевые слова: эспариет песчаный, сорта, полевая всхожесть, густота всходов, урожайность, биохимический состав.

Расширение ассортимента видов и сортов трав является наиболее действенным и экономически выгодным направлением хозяйственной деятельности. Одной из перспективных культур для Пермского края может быть эспарцет песчаный, который в местных условиях до сих пор не возделывается, но встречается в естественной флоре в Кунгурском, Ординском и Суксунском районах.
Эспарцет песчаный Onobrýchis arenária (Kit.) - многолетнее травянистое растение, вид рода эспарцет (Onobrýchis, Mill) семейства бобовые (Fabaceae) с коротким периодом вегетации и высокой зимостойкостью [2] (рис.). Относится к растениям ярового типа развития, на второй год жизни быстро отрастает и образует два укоса за сезон [6, с. 69-74]. По кормовым достоинствам не уступает люцерне 


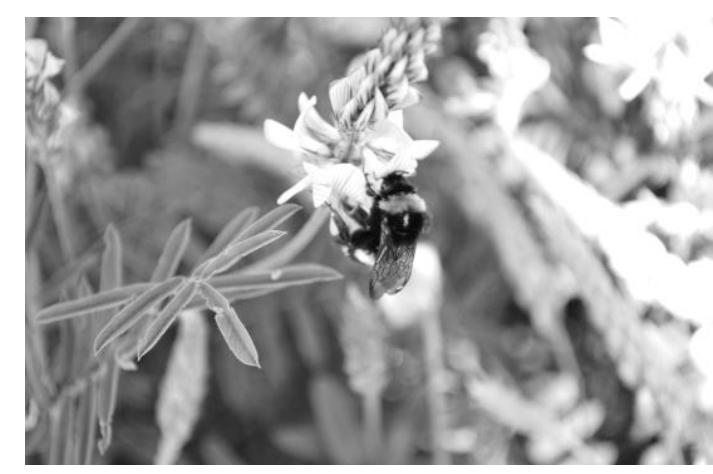

Puc. Эспариет песчаныıй Onobrýchis arenária (Kit.)

и клеверу [1, с. 14-16; 4, с. 23-25; 8, с. 9-12; 9, с. 29-30]. В Пермском крае ранее не возделывался, поэтому разработка приемов его выращивания весьма актуальна.

Цель исследований - сравнительная оценка сортов эспарцета песчаного различных селекционных центров России на кормовые цели в Предуралье.

На начальном этапе научных исследований была поставлена задача получить экспериментальные данные по росту и развитию сортов в год посева и в 1-й год пользования травостоем.

\section{Методика и условия проведения исследований}

Объект исследования - сорта эспарцета песчаного. Исследования проведены в однофакторном полевом опыте в двух последовательных во времени закладках: 14 мая 2015 и 10 июня 2016 года, выполненных на опытном участке Пермского НИИСХ ФИЦ УрО РАН. Почва опытного участка дерново-подзолистая тяжелосуглинистая со следующей характеристикой пахотного горизонта: 1-я закладка (2015 год посева) - содержание гумуса 2,32\%, pH 4,98, содержание подвижных форм фосфора 162,0 мг/кг почвы, 2-я закладка (2016 год посева) - гумус - 2,66\%, pH 4,76, содержание подвижных форм фосфора 252,5 мг/кг почвы. При проведении полевых опытов и лабораторных исследований использованы общепринятые методики [3, 28-200; 7, с. 15-126]. Норма высева 4 млн всхожих семян/га, способ посева рядовой, беспокровный. Расположение вариантов рендомизированнное. Повторность четырехкратная. Учет урожайности зеленой массы проводили в фазу начала цветения растений. Обработка полученных данных проводилась с помощью дисперсионного и корреляционного анализов.

\section{Результаты исследований}

Густота всходов и полевая всхожесть зависели, прежде всего, от условий увлажнения почвы в период «посев-всходы». При удовлетворительном увлажнении почвы в 2015 году полевая всхожесть варьировалась в пределах от 36,2 до 73,9\%. В 2016 году при дефиците почвенной влаги этот показатель был ниже в среднем на 5,3\% (табл. 1). По густоте всходов и полевой всхожести выделился сорт Павловский -259 шт $/ \mathrm{M}^{2}$ и $58,9 \%$ соответственно, в среднем по двум закладкам, у остальных сортов эти показатели были на $7,1-17,8 \%$ ниже.

В 1-й закладке, при благоприятных условиях, в 2015 году начало всходов отмечено к 23-25 мая, полные всходы 25-27 мая, т.е. через 15-20 дней после посева. Начало стеблевания растений отмече-

Таблиияа 1

Густота всходов, полевая всхожесть эспарцета песчаного сортов эспарцета песчаного при возделывании на зеленую массу (2015 - 2016 годов посева)

\begin{tabular}{|c|c|c|c|c|c|c|}
\hline \multirow[b]{2}{*}{$\begin{array}{c}\text { Вариант } \\
\text { (сорт) }\end{array}$} & \multicolumn{2}{|c|}{$\begin{array}{c}2015 \\
\text { год посева }\end{array}$} & \multicolumn{2}{|c|}{$\begin{array}{c}2016 \\
\text { год посева }\end{array}$} & \multicolumn{2}{|c|}{$\begin{array}{l}\text { Среднее } \\
\text { за } 2 \text { года }\end{array}$} \\
\hline & $\begin{array}{c}\text { Кол-во } \\
\text { всходов, } \\
\text { шт./M² }\end{array}$ & $\begin{array}{c}\text { Полевая } \\
\text { всхожесть, } \\
\%\end{array}$ & $\begin{array}{c}\text { Кол-во } \\
\text { всходов, } \\
\text { шт./M² }\end{array}$ & $\begin{array}{c}\text { Полевая } \\
\text { всхожесть, } \\
\%\end{array}$ & $\begin{array}{c}\text { Кол-во } \\
\text { всходов, } \\
\text { шт./M² }\end{array}$ & $\begin{array}{c}\text { Полевая } \\
\text { всхожесть,\% }\end{array}$ \\
\hline СибНИИК-30 & 238 & 57,6 & 192 & 46,0 & 215,0 & 51,8 \\
\hline Петушок & 239 & 58,4 & 194 & 47,9 & 216,5 & 53,2 \\
\hline Михайловский-10 & 146 & 36,2 & 188 & 46,0 & 167,0 & 41,1 \\
\hline Песчаный 22 & 179 & 43,9 & 212 & 51,0 & 195,5 & 47,5 \\
\hline Павловский & 300 & 73,9 & 218 & 52,8 & 259,0 & 58,9 \\
\hline
\end{tabular}


Прохождение основных фенофаз сортов эспарцета песчаного первого года жизни при возделывании на зеленую массу (2015 - 2016 года посева)

\begin{tabular}{|c|c|c|c|c|c|}
\hline \multirow{2}{*}{ Вариант опыта } & \multirow{2}{*}{ Посев } & \multicolumn{2}{|c|}{ Всходы } & \multicolumn{2}{|c|}{ Стеблевание } \\
\hline & & нач. & полн. & нач. & полн. \\
\hline СибНИИК-30 & \multirow{5}{*}{14.05 .15} & 24.05 & 26.05 & 5.06 & - \\
\hline Петушок & & 24.05 & 26.05 & 5.06 & - \\
\hline Михайловский-10 & & 25.05 & 27.05 & 6.06 & - \\
\hline Песчаный 22 & & 24.05 & 26.05 & 5.06 & - \\
\hline Павловский & & 23.05 & 25.05 & 5.06 & - \\
\hline СибНИИК-30 & \multirow{5}{*}{3.06 .16} & 22.06 & 27.06 & 19.07 & 28.07 \\
\hline Петушок & & 22.06 & 26.06 & 23.07 & 3.08 \\
\hline Михайловский-10 & & 21.06 & 25.06 & 22.07 & 29.07 \\
\hline Песчаный 22 & & 22.06 & 27.06 & 21.07 & 29.07 \\
\hline Павловский & & 22.06 & 25.06 & 21.07 & 1.08 \\
\hline
\end{tabular}

но 5-7 июня. Укосной массы в этот год не сформировалось (табл. 2).

При неудовлетворительном запасе продуктивной влаги (ЗПВ) практически во время всего сезона 2016 года всходы начали появляться 25-27 июня, полные всходы отмечены через 18-19 дней после посева, что характерно для эспарцета песчаного [2, с. $106-112 ; 4$, с. $18-20 ; 5$, с. 87-100; 10, с. 17-27]. Эспарцет песчаный, следовательно, является очень пластичной культурой в отношении реакции на условия увлажнения. Начало стеблевания растений в этой закладке отмечено 19-23 июня.

Погодные условия Пермского края, несмотря на их контрастность, вполне пригодны для получения всходов и формирования розетки листьев.

Первая закладка после перезимовки была выбракована вследствие затопления растений талой водой весной и последующей гибели от вымокания. Далее описание результатов исследований дается по 2-й закладке, на которой после первой зимы получена хорошая перезимовка растений эспарцета песчаного.

Можно отметить, что все изучаемые сорта при прохладном вегетационном периоде 2017 года, но при обилии осадков, дали 2 укоса с разницей по прохождению всех фенофаз между сортами в 1-4 дня (табл. 3).

Период от отрастания до начала цветения (на формирования первого укоса) составил 64-69 дней, второй укос провели через 2 месяца после первого, т.е. при достаточной увлажненности почвы, в условиях даже прохладной погоды эспарцет песчаный в Пермском крае сформировал 2 полноценных укоса.

Максимальный сбор абсолютно сухой массы в целом за сезон - 6,24 т/га получен у сорта СибНИИК-30, наименее урожайным оказался сорт Павловский $4,21 \mathrm{~T} / г \mathrm{a}$, при величине $\mathrm{HCP}_{0,5}-1,97$. Сорт Петушок, Михайловский-10 и Песчаный 22 обеспечили практически равный сбор корма 5,44-5,78 т/га. Но при

Таблица 3

Прохождение основных фенофаз сортов эспарцета песчаного при возделывании на зеленую массу второго года жизни (2016 года посева)

\begin{tabular}{|c|c|c|c|c|c|c|c|c|c|c|}
\hline \multirow{2}{*}{$\stackrel{0}{\circ}$} & \multirow{2}{*}{ Сорт } & \multicolumn{2}{|c|}{ Отрастание } & \multicolumn{2}{|c|}{ Стеблевание } & \multicolumn{2}{|c|}{ Бутонизация } & \multicolumn{2}{|c|}{ Цветение } & \multirow{2}{*}{$\begin{array}{l}\text { Дата } \\
\text { укоса }\end{array}$} \\
\hline & & нач. & полн. & нач. & полн. & нач. & полн. & нач. & полн. & \\
\hline \multirow{5}{*}{1} & СибНИИК-30 & 28.04 & 2.05 & 17.05 & 25.05 & 23.06 & 27.06 & 5.07 & 11.07 & 11.07.17 \\
\hline & Петушок & 28.04 & 2.05 & 19.05 & 27.05 & 23.06 & 27.06 & 7.07 & - & 11.07.17 \\
\hline & Михайловский-10 & 29.04 & 4.05 & 19.05 & 27.05 & 23.06 & 27.06 & 9.07 & - & 11.07.17 \\
\hline & Песчаный 22 & 28.04 & 2.05 & 17.05 & 25.05 & 23.06 & 27.06 & 7.07 & - & 11.07.17 \\
\hline & Павловский & 28.04 & 2.05 & 16.05 & 27.05 & 25.06 & 29.06 & 7.07 & - & 11.07.17 \\
\hline \multirow{5}{*}{2} & СибНИИК-30 & 22.07 & 24.07 & 31.07 & 5.08 & 26.08 & 2.09 & 12.09 & - & 14.09.17 \\
\hline & Петушок & 22.07 & 25.07 & 1.08 & 5.08 & 25.08 & 3.09 & 12.09 & - & 14.09.17 \\
\hline & Михайловский-10 & 21.07 & 25.07 & 1.08 & 5.08 & 25.08 & 2.09 & 11.09 & - & 14.09.17 \\
\hline & Песчаный 22 & 23.07 & 27.07 & 2.08 & 6.08 & 26.08 & 04.09 & 12.09 & - & 14.09.17 \\
\hline & Павловский & 23.07 & 26.07 & 3.08 & 6.08 & 26.08 & 04.09 & 14.09 & - & 14.09.17 \\
\hline
\end{tabular}


этом необходимо отметить разное распределение урожая по укосам: сорта СибНИИК-30, Петушок и Михайловский-10 - 70-75\% урожая сформировали в I укосе. Практически равномерное распределение урожая 55 и 45\% по укосам обеспечил сорт Павловский (табл. 4).

Результаты анализа структуры урожайности образцов, отобранных в 2017 году, показали, что в первом укосе по высоте растений выделились сорта СибНИИК-30 и Песчаный 22 достигнув высоты 87 и 91 см соответственно, у сорта Павловский высота растений была существенно ниже - на 10-14 см, при $\mathrm{HCP}_{05}-$ 9,07, по остальным двум сортам существенной разницы по высоте не прослежено. Наибольшее количество побегов получено у сорта СибНИИК-30 - 292 шт./м², что не существенно выше, чем у других сортов, за исключением сорта Павловский, у которого этот показатель оказался самым низким - 170 шт./м². Самая большая масса 1 побега получена у сорта Петушок 8,79 г, но разница между вариантами находилась в пределах ошибки опыта $(\mathrm{F} \phi<\mathrm{FT})$ Доля листьев в структуре зеленой массы находилась в пределах 51,3-55,3\%.

Анализ структуры урожая 2-го укоса показал, что по всем элементам существенной разницы между сортами нет. Высота растений была в пределах от 71 до $79 \mathrm{cm,} \mathrm{количество} \mathrm{побегов} \mathrm{76-}$ 93 шт./м², масса 1 побега от 9,17 до 11,32 г, в урожае зеленой массы на долю листьев приходится 53-67 \%. При этом показатели структуры урожайности во 2-м укосе, такие как число побегов, масса листьев и стеблей, оказались более чем в два раза ниже, чем в 1-м укосе, по всем сортам, однако масса 1 побега уменьшилась незначительно, а у сорта Петушок даже увеличилась с 7,51 до 8,79 г. Необходимо отметить, что при более низкой урожайности весовая доля листьев в структуре урожая второго укоса, по сравнению с первым, была выше на 3,3-15,0\% (табл. 5).

Биохимический анализ зеленой массы 5 сортов эспарцета песчаного второго года жизни показал ее высокую питательную ценность (табл. 6), однако сравнивать биохимический состав сортов по результатам одного года преждевременно; исследования следует продолжить.

Полученные результаты в дальнейшем будут полезны для работы Государственной комиссии РФ по испытанию и охране селекционных достижений при формировании Государственного реестра сортов (селекционных достижений), допущенных к использованию на территории различных регионов России.

\section{Выводы}

1. Природные условия центральных районов Пермского края позволяют возделывать перспективную бобовую культуру - эспарцет песчаный.

2. Максимальный сбор абсолютно сухой массы в целом за сезон - 6,24 т/га - получен у сорта СибНИИК-30, наименее урожайным оказался сорт Павловский 4,21 т/га. Сорта Петушок, Михайловский-10 и Песчаный 22 обеспечили практически равный сбор корма 5,44-5,78 т/га.

3. Сорта СибНИИК-30, Петушок и Михайловский-10 сформировали большую часть общей урожайности в первом укосе - 70-75\%. Практически равномер-

Таблица 4

Урожайность сортов эспарцета песчаного при возделывании на зеленую массу второго года жизни (2016 года посева)

\begin{tabular}{|c|c|c|c|c|c|c|}
\hline \multirow{3}{*}{ Сорт } & \multicolumn{4}{|c|}{ Урожайность, т/га } & \multicolumn{2}{|c|}{ Сумма за два укоса, т/га } \\
\hline & \multicolumn{2}{|c|}{ зеленой массы } & \multicolumn{2}{|c|}{ сухой массы } & \multirow{2}{*}{$\begin{array}{c}\text { зеленой } \\
\text { массы }\end{array}$} & \multirow{2}{*}{$\begin{array}{c}\text { сухой } \\
\text { массы }\end{array}$} \\
\hline & І укос & II укос & І укос & II укос & & \\
\hline СибНИИК-30 & 23,8 & 8,6 & 4,35 & 1,90 & 32,4 & 6,24 \\
\hline Петушок & 21,6 & 6,4 & 4,35 & 1,43 & 28,0 & 5,78 \\
\hline Михайловский-10 & 21,4 & 7,5 & 4,06 & 1,70 & 28,9 & 5,76 \\
\hline Песчаный 22 & 20,2 & 8,4 & 3,65 & 1,79 & 28,6 & 5,44 \\
\hline Павловский & 11,7 & 8,5 & 2,33 & 1,88 & 20,2 & 4,21 \\
\hline $\mathrm{HCP}_{05}$ * & 8,3 & $\mathrm{~F} \phi<\mathrm{FT}_{\mathrm{T}}$ & $\mathrm{F} \phi<<\mathrm{FT}_{\mathrm{T}}$ & $\mathrm{F} \phi<<\mathrm{FT}$ & 8,6 & 1,97 \\
\hline
\end{tabular}

\footnotetext{
Примечание: * - наименьшая существенная разница.
} 
Элементы структуры урожайности зеленой массы сортов эспарцета песчаного на 1-м укосе 2-го года жизни (2016 года посева)

\begin{tabular}{|c|c|c|c|c|c|c|c|c|c|}
\hline \multirow{3}{*}{ 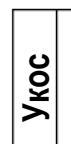 } & \multirow{3}{*}{ Сорт } & \multirow{3}{*}{$\begin{array}{c}\text { Высота } \\
\text { растений, } \\
\text { см }\end{array}$} & \multirow{3}{*}{$\begin{array}{c}\text { Число } \\
\text { побегов, } \\
\text { шт/M² }\end{array}$} & \multicolumn{5}{|c|}{ Зеленая масса, кг/м² } & \multirow{3}{*}{$\begin{array}{c}\text { Масса } \\
\text { одного } \\
\text { побега, г }\end{array}$} \\
\hline & & & & \multirow{2}{*}{ Всего } & \multicolumn{4}{|c|}{ В том числе } & \\
\hline & & & & & листья & $\%$ & стебли & $\%$ & \\
\hline \multirow{7}{*}{1} & СибНИИК-30 & 87 & 292 & 2,34 & 1,29 & 55,3 & 1,05 & 44,7 & 8,02 \\
\hline & Петушок & 83 & 241 & 2,12 & 1,11 & 52,2 & 1,01 & 47,8 & 8,79 \\
\hline & Михайловский-10 & 81 & 287 & 2,13 & 1,09 & 51,3 & 1,04 & 48,7 & 7,40 \\
\hline & Песчаный 22 & 91 & 265 & 2,05 & 1,12 & 54,5 & 0,93 & 45,5 & 7,74 \\
\hline & $\begin{array}{c}\text { Павловский } \\
\text { песчаный }\end{array}$ & 77 & 170 & 1,22 & 0,63 & 51,4 & 0,59 & 48,6 & 7,19 \\
\hline & $\mathrm{HCP}_{05}$ & 9,07 & 76 & 0,74 & 0,56 & - & 0,23 & - & $\mathrm{F} \phi<<\mathrm{F}$ \\
\hline & Коэф. кор. & 0,64 & 0,93 & - & 0,99 & - & 0,99 & - & 0,59 \\
\hline \multirow{7}{*}{2} & СибНИИК-30 & 79 & 85 & 0,87 & 0,51 & 58,8 & 0,36 & 41,2 & 10,19 \\
\hline & Петушок & 74 & 88 & 0,66 & 0,44 & 67,0 & 0,22 & 33,0 & 7,51 \\
\hline & Михайловский-10 & 71 & 82 & 0,78 & 0,47 & 59,3 & 0,32 & 40,7 & 9,57 \\
\hline & Песчаный 22 & 75 & 93 & 0,85 & 0,45 & 53,0 & 0,40 & 47,0 & 9,17 \\
\hline & $\begin{array}{c}\text { Павловский } \\
\text { песчаный }\end{array}$ & 76 & 76 & 0,86 & 0,56 & 65,6 & 0,30 & 34,4 & 11,32 \\
\hline & $\mathrm{HCP}_{05}$ & $\mathrm{~F} \phi<\mathrm{FT}_{\mathrm{T}}$ & F $\phi<F T$ & $\mathrm{~F} \phi<<\mathrm{FT}$ & F $\phi<F T$ & - & F $\phi<F T$ & - & $\mathrm{F} \phi<<\mathrm{F}$ \\
\hline & Коэф. кор. & 0,60 & $-0,20$ & - & 0,64 & - & 0,81 & - & 0,83 \\
\hline
\end{tabular}

Биохимический состав абсолютно сухой массы сортов эспарцета

Таблица 6 песчаного 2-го года жизни (2016 года посева)

\begin{tabular}{|c|c|c|c|c|c|c|c|c|c|}
\hline $\begin{array}{l}\stackrel{0}{2} \\
\grave{\lambda}\end{array}$ & Вариант (сорт) & \begin{tabular}{|c|} 
Сухое \\
вещество \\
$\%$
\end{tabular} & $\begin{array}{l}\text { Сырой } \\
\text { жир,\% }\end{array}$ & $\begin{array}{c}\text { Сырая } \\
\text { клетчатка, } \\
\%\end{array}$ & $\begin{array}{c}\text { Сырая } \\
\text { зола, } \\
\%\end{array}$ & $\begin{array}{c}\text { Сырой } \\
\text { протеин, } \\
\%\end{array}$ & $\begin{array}{c}\text { Caxap, } \\
\%\end{array}$ & $\begin{array}{c}\text { Обменная } \\
\text { энергия, } \\
\text { МДж/кг }\end{array}$ & $\begin{array}{c}\text { Kopм } \\
\text { eд., } \\
\text { кг/кг }\end{array}$ \\
\hline \multirow{6}{*}{1} & СибНИИК-30 & 19,62 & 2,42 & 22,31 & 7,28 & 15,09 & 10,13 & 10,99 & 0,98 \\
\hline & Петушок & 22,94 & 1,91 & 25,79 & 6,85 & 14,60 & 7,81 & 10,36 & 0,87 \\
\hline & Михайловский-10 & 20,01 & 1,58 & 26,10 & 6,34 & 13,19 & 8,68 & 10,64 & 0,87 \\
\hline & Песчаный 22 & 22,51 & 1,60 & 24,69 & 6,59 & 12,61 & 8,34 & 10,56 & 0,90 \\
\hline & $\begin{array}{c}\text { Павловский } \\
\text { песчаный }\end{array}$ & 20,28 & 1,72 & 23,08 & 6,48 & 12,32 & 11,06 & 10,84 & 0,95 \\
\hline & $\mathrm{HCP}_{05}$ & $\mathrm{~F} \phi<\mathrm{FT}$ & 0,62 & F $\phi<\mathrm{FT}_{\mathrm{T}}$ & 0,87 & F $\phi<\mathrm{FT}_{\mathrm{T}}$ & $\mathrm{F} \phi<<\mathrm{FT}$ & F $\phi<F T$ & F $\phi<F T$ \\
\hline \multirow{6}{*}{2} & СибНИИК-30 & 22,14 & 2,81 & 25,59 & 5,80 & 15,94 & 6,23 & 10,39 & 0,88 \\
\hline & Петушок & 22,49 & 2,55 & 27,40 & 6,23 & 17,01 & 5,28 & 10,07 & 0,82 \\
\hline & Михайловский-10 & 21,64 & 2,88 & 21,51 & 6,50 & 17,05 & 6,34 & 11,13 & 1,00 \\
\hline & Песчаный 22 & 20,52 & 2,47 & 22,75 & 6,50 & 17,26 & 6,38 & 10,91 & 0,97 \\
\hline & $\begin{array}{c}\text { Павловский } \\
\text { песчаный }\end{array}$ & 22,25 & 2,55 & 25,13 & 6,84 & 15,01 & 5,15 & 10,48 & 0,89 \\
\hline & $\mathrm{HCP}_{05}$ & F $\phi<F T$ & F $\phi<F T$ & $\mathrm{~F} \phi<<\mathrm{T}$ & F $\phi<F T$ & $\mathrm{~F} \phi<<\mathrm{F}$ & $\mathrm{F} \phi<<\mathrm{FT}$ & 0,85 & Fop $<\mathrm{FT}$ \\
\hline
\end{tabular}

ное распределение урожая: 55 и $45 \%$ по укосам обеспечил сорт Павловский.

4. Биохимический анализ зеленой массы пяти сортов эспарцета песчаного показал, что данная кормовая культура обладает высокой питательной ценностью для сельскохозяйственных животных.

\section{Библиографический список}

1. Денисов Е.П., Косачев А.М., Марс А.М., [и др.] Перспективные бобовые кормовые культуры для сухостепной зоны // Кормопроизводство. - 2011. - № 2. - С.14-16.

2. Дзюбенко Н.И., Абдушаева Я.М. Адаптация американских экотипов Onobrýchis arenária (Kit) Ser. В условиях Новгородской области // Сельскохозяйственная биология. - 2012. - № 4. - С. 106-112.

3. Доспехов Б.А. Методика полевого опыта. - М.: Колос, 1985. - 336 с.

4. Каращук И.М. Эспарцет в Западной Сибири. - Новосибирск: Зап.-Сиб. кн. изд-во, 1978. - 78 с. 
5. Люшинский В.В., Прижуков Ф.Б.Эспарцет // Семеноводство многолетних трав. - М.: Колос, 1973. C. $87-100$.

6. Максимов Д.С. Агротехника высоких урожаев многолетних трав. - М.: Россельхозиздат,1966. - 176 с.

7. Методика опытов на сенокосах и пастбищах [Текст] / Всесоюз. науч.-исслед. ин-т кормов им. В.Р. Вильямса - М., 1971. -229 с.

8. Панков Д.М. Возделывание эспарцета песчаного (onobryhis arenaria (d.c.) на корм в лесостепи алтайского края // Вестник Алтайского государственного аграрного университета. - 2009. № 9 (59). - C. 9-12.

9. Сагалбеков У.М., Сагалбеков Е.У. Сорта многолетних трав для Западной Сибири и Северного Казахстана // Кормопроизводство. - 2012. - № 9. - С. 29-30.

10. Кириченко I.I. Эспарцет - у кожне господарство. - Донецьк: Видавництво «Донбас», 1974. - 144 с.

\title{
THE COMPARATIVE EVALUATION OF SANDY SAINFOIN Onobrýchis arenária (Kit.) VARIETIES GROWN FOR GREEN MASS IN THE MIDDLE PRE-URALS
}

\author{
N.N. Matolinets, V.A. Voloshin \\ Perm Agricultural Research Institute
}

The article presents the results of the comparative evaluation of sandy sainfoin Onobrýchis arenária (Kit.) five varieties breeded in different selection centers in the conditions of the Perm Region. The seedlings density, the field germination, the main phenophases dynamics, overwintering, green and dry matter yield data are reported. It was determined that all varieties of sandy sainfoin under weather conditions in 2015 - 2016 showed the winter type of development in the first year of their life. In the second year of their life the maximum gain of absolutely dry matter per season - 6,24 t/ha was obtained for the SIBNIK 30 variety, the minimum yield was obtained from Pavlovsky cultivar $-4,21 \mathrm{t} / \mathrm{ha}$. Biochemical analysis of the green mass of five varieties of sandy sainfoin showed that this forage crop has a high nutritional value for agricultural animals. The fulfilled studies showed the possibility of sandy sainfoin introduction to arable farming in the Middle Pre-Urals, but task-oriented breeding of this crop for regional conditions is necessary. The results obtained in the future will be useful for the work of the State Commission of the Russian Federation on testing and protection of breeding achievements in the formation of the State Register of varieties (breeding achievements) approved for use in various regions of Russia.

Keywords: sandy sainfoin, varieties, field germination, germination density, yield, biochemical composition.

\section{Сведения об авторах}

Матолинеи Николай Николаевич, научный сотрудник лаборатории кормопроизводства, животноводства и ветеринарной медицины, Пермский научно-исследовательский институт сельского хозяйства - филиал Пермского федерального исследовательского центра УрО РАН (Пермский НИИСХ), 614532, Пермский край, Пермский район, с. Лобаново, ул. Культуры, 12; e-mail: matolinets-nikolay@mail.ru

Волошин Владимир Алексеевич, доктор сельскохозяйственных наук, главный научный сотрудник лаборатории кормопроизводства, животноводства и ветеринарной медицины, Пермский НИИСХ; e-mail: pniish@rambler.ru 